\title{
Nickel-isotope cycling on the Namibian margin
}

\author{
TIM SWEERE ${ }^{1}$, KRISTIN ANNA UNGERHOFER ${ }^{2}$, \\ NOLWENN LEMAITRE ${ }^{3}$, PETER KRAAL ${ }^{4}$ AND DEREK \\ VANCE $^{3}$
}

${ }^{1}$ ETH Zürich

${ }^{2}$ Royal Netherlands Institute for Sea Research (NIOZ)

${ }^{3}$ ETH Zürich

${ }^{4}$ Royal Netherlands Institute for Sea Research

Presenting Author: tim.sweere@erdw.ethz.ch

Nickel (Ni) is a bio-essential trace metal with a nutrient-like distribution in the modern ocean. The element is part of several enzymes with important functions in the carbon, nitrogen, and sulphur cycles. Nickel concentrations of organic-rich sediments strongly correlate with total-organic carbon content, but the element is also strongly influenced by $\mathrm{Fe}$-and Mn-oxide cycling. Ocean redox conditions will therefore have an impact on the global mass balance of $\mathrm{Ni}$ as well as internal cycling in the ocean. Evaluating the role and availability of $\mathrm{Ni}$ as a micronutrient in past and present oceans thus requires a more detailed understanding of its behaviour in different redox conditions. Recent developments in Ni-isotope analysis allow for the quantification of fluxes in and out of the ocean and can reveal processes that affect internal Ni cycling. So far, these studies have shown an unbalanced $\mathrm{Ni}$-isotope mass balance, meaning some sources or sinks of $\mathrm{Ni}$ are currently not characterised.

Here, we present Ni-isotope data from Namibian Margin sediments, sea water, and pore water. The highly productive upwelling system causes anoxic conditions on the shelf at $\sim 100 \mathrm{~m}$ depth and a wider oxygen minimum zone on the slope between $\sim 200$ and $400 \mathrm{~m}$ depth, below which conditions become increasingly more oxygenated. The Namibian margin therefore allows the study of Ni-isotope systematics in a large range of redox conditions within one setting. We present data from four different stations, with conditions ranging from fully anoxic to oxic. By comparison of the $\mathrm{Ni}$-isotope data to major nutrient and redox indicators, we evaluate the $\mathrm{Ni}$-isotope behaviour in these different redox conditions and the relevance of such environments for the global isotopic mass balance of the element. The data suggest that reducing sediments may represent a relevant source of isotopically heavy $\mathrm{Ni}$ to the ocean that could close the global isotopic mass balance. 